\title{
Electrochemical Performance of AZ31 Magnesium Alloy under Different Processing Conditions
}

\author{
Deng Jinfeng ${ }^{1}$, Huang Guangsheng ${ }^{1,2}$, Zhao Yanchun ${ }^{1}, \quad$ Wang Bei ${ }^{1}$ \\ ${ }^{1}$ National Engineering Research Center for Magnesium Alloys, Chongqing University, Chongqing 400045, China; ${ }^{2}$ Chongqing Research \\ Center for Advanced Materials, Chongqing Academy of Science \& Technology, Chongqing 401123, China
}

\begin{abstract}
In order to select a good cost-performance ratio magnesium alloy as anode material, the electrochemical properties of AZ31B magnesium alloy under different processing conditions were investigated by electrochemical workstation, optical microscope (OM), scanning electron microscopy (SEM) and energy dispersed spectroscopy (EDS). Extruded, rolled, cast-rolled and as-cast AZ31 magnesium alloys were prepared as the anode materials. The results show that under different processing conditions, the extruded alloy is the best cost-performance ratio anode material among the four alloys. It possesses the most negative equilibrium potential, the lowest corrosion current density and the smallest free corrosion rate indicating the highest electrochemical activity due to the uniform fine grains and the second phase. Its corrosiun products are loose, dispersing uniformly on the extruded anode surface, prone to falling off which decrease the polarization and increase the utilization of the anode. The electrochemical activity and the corrosion resistance of the rolled and the cast-rolled alloys are relatively low, compared with the extrude samples. Due to the coarse grains, as-cast defects and coarse second phase distributed along the grain boundaries, the as-cast alloy has unstable discharge curve and positive discharge potential. The corrosions of AZ31 magnesium alloy under different conditions are almost pitting corrosion.
\end{abstract}

Key words: AZ31 magnesium alloy; current density; discharge; corrosion

Among the lightest structural metals, magnesium alloy possess high theoretical specific capacity, high chemical activity, low standard electrode potential and abundant resources, which make it a broad prospect as a battery anode material ${ }^{[1]}$. Many researches about magnesium alloy as anodes have been developed extensively in applications, such as anodic protection $^{[2-5]}$, torpedo ${ }^{[6,7]}$, ocean buoys, missiles, magnesiumbased hydrogen storage alloy ${ }^{[8-10]}$, fuel cells, water-activated batteries $^{[11]}$, etc. However, as the anode material, magnesium alloy also has some drawbacks, such as voltage delay, negative difference effect and severe free corrosion. At present, the researches of magnesium anode materials mainly focus on the following aspects: the mechanism, surface treatment ${ }^{[12]}$, the improvement of the composition ${ }^{[14]}$ and internal organization ${ }^{[13]}$.

Microstructure has a great influence on the electrochemical performance. Many experiments have been conducted by different heat treatment methods to study the electrochemical properties and the corrosion mechanism of magnesium alloys $^{[11,15,16]}$. Naing Naing Aung, et al. ${ }^{[17]}$ suggested that the twins appear to accelerate the intergranular corrosion. In the absence of twins, the grain size plays an important role in the corrosion resistance, and the corrosion rate rises with the increasing of grain size.

AZ31 magnesium alloy under different processing conditions exhibits different microstructures, resulting in different electrochemical performances. At present, magnesium alloy for battery is mainly processed by rolling or as-cast. The high cost of rolling process makes the use of the magnesium alloy for electrochemical application limited, only in telecommunications batteries, torpedoes and other few areas. Magnesium has only a few slip systems at room temperature due to the

$\overline{\text { Received date: February 05, }} 2013$

Foundation item: Ministry of Science and Technology of China (2008DFR50040); Scientific and Technological Project of Chongqing Science and Technology Commission (CSTC2010AA4035)

Corresponding author: Huang Guangsheng, Ph. D., Professor, College of Material Science and Engineering, Chongqing University, Tel: 0086-23-65112239, E-mail: gshuang@cqu.edu.cn

Copyright (C) 2014, Northwest Institute for Nonferrous Metal Research. Published by Elsevier BV. All rights reserved. 
hexagonal close-packed structure. Plastic deformation difficulties and high cost become serious impediments for large-scale application of magnesium battery. The costs of AZ31 magnesium alloy under the different processing conditions are different. As-cast has simple processing, resulting in lower processing cost; extrusion, due to the three-force press, deforms more easily than rolling. Therefore, extruded magnesium alloys exhibit a relatively low processing cost. Compared with rolling, the cost of cast-rolling decreases relatively. Nevertheless, there is little research in the process technique effect on the corrosion performance. This article researched the electrochemical properties of AZ31 magnesium alloy under different processing conditions to select an optimal processing for magnesium alloy as battery anode material.

\section{Experiment}

AZ31 magnesium alloys were used in the experiment. The extruded, rolled, cast-rolled, as-cast AZ31 magnesium alloys were prepared as the working electrode, respectively. The as-cast samples were cut from a cylindrical ingots with a diameter of $85 \mathrm{~mm}$ poured by a permanent mould; the extruded magnesium alloys were strips prepared by hot extrusion; the rolled materials were produced through hot rolling, warm rolling, and cold rolling, followed by annealing; Cast-rolled AZ31 magnesium alloy was a kind of cast-rolling strip through warm rolling with $60 \%$ deformation. Electrolyte used in the experiment was $3.5 \%$ (mass fraction) $\mathrm{NaCl}$. Electrochemical performance tests were carried through the electrochemical workstation. The cell setup was composed of a standard three-electrode system, with a saturated calomel electrode (SCE) (0.242 V vs SHE) as the reference electrode. The thin platinum electrode worked as the auxiliary electrode.

The samples $(30 \mathrm{~mm} \times 10 \mathrm{~mm} \times 0.6 \mathrm{~mm})$ were successively polished, carefully degreased with acetone and rinsed with distilled water and alcohol, followed by ultrasonic cleaning for $5 \mathrm{~min}$. Then the samples were packed with the acrylic acid, leaving the work area of $10 \mathrm{~mm} \times 10 \mathrm{~mm}$ as the work electrode, afterward dried by warm air for later use. The microstructures and morphologies of the corroded surfaces were analysed using optical microscope and SEM coupled with EDS system.

During the Tafel test, working electrode was immersed in the $3.5 \% \mathrm{NaCl}$ solution for $120 \mathrm{~s}$. Then the test was carried on at a constant scanning speed of $0.01 \mathrm{~V} / \mathrm{s}$, and its initial potential was set to $-0.4 \mathrm{~V}$.

The initial mass and area of the samples were accurately measured before the self-corrosion test. Then the samples were hanged and immerged in $3.5 \% \mathrm{NaCl}$ electrolyte for 70 h. After that, the samples were cleaned by chromic acid of 250 $\mathrm{g} / \mathrm{L}$, followed by ultrasonic washing at room temperature. The accurate mass of samples after self-corrosion test was measured. The sample after free corrosion test was cleaned by distilled water and ultrasonic washing before SEM test. Self-discharge rate can be expressed as:

$$
J=\frac{\left(m_{0}-m_{1}\right) \times 2 \times 96500}{24 S t}
$$

where $J$ is free corrosion rate, $\mathrm{mA} / \mathrm{cm}^{2} ; m_{0}$ is initial mass and $m_{1}$ is accurate mass of samples after self-corrosion test, $\mathrm{mg} ; t$ is for time, $\mathrm{s} ; S$ is area, $\mathrm{cm}^{2}$.

Electrochemical impedance spectroscopy (EIS) was measured in the frequency range of $10^{-1} \sim 10^{5} \mathrm{~Hz}$. The initial potential was open circuit potential determined by Tafel polarization curves and the exchange potential amplitude was $5 \mathrm{mV}$. The working electrode was immersed in electrolyte for $300 \mathrm{~s}$ before the experiment to obtain a stable testing system.

Chrono-potentiometry was used to study the discharge process. Anode current was set to $-0.05 \mathrm{~mA}$ and the work electrode was immerged in $\mathrm{NaCl}$ solution for $600 \mathrm{~s}$. All tests were carried out at ambient temperature. Each test was carried out more than five times to get an average result.

\section{Results and Discussion}

\subsection{Microstructure}

Fig.1 shows the optical microstructures of the AZ31 magnesium alloy under different processing conditions. The as-cast grains are apparently coarser and larger than the others. The extruded sample exhibits relatively fine grains. The grains of the rolled magnesium alloy are roughly equiaxed and disperse uniformly. The rolled and cast-rolled alloys have irregular grain boundaries and the grains do not disperse uniformly compared to those of extruded magnesium alloys. There are no obvious twins in the four states of magnesium alloys.

Fig. 2 shows the SEM images of AZ31 magnesium alloy under different processing conditions. Fig. 3 presents the EDS results of point $\mathrm{A}$ and point $\mathrm{B}$ in Fig.2a. According to the results, most of the second phase in $\mathrm{AZ31}$ alloy is $\mathrm{Mg}_{17} \mathrm{Al}_{12}$, meanwhile Al-Mn particles can be also found in the matrix (see point A in Fig.2a). Due to the large plastic deformation, large bulk $\mathrm{Mg}_{17} \mathrm{Al}_{12}$ phase is broken and distributed along the direction of extrusion. The second phase is fine and homogeneous. The second phase in the cast-rolled alloy is relatively fine and distributed homogeneously in grains or along the grain boundaries; the second phase is broken and fine in the rolled alloy. They are not distributed homogeneously as those in the as-cast alloy. In the as-cast magnesium alloy, around the island-like phase, there exist phases distributed layer-by-layer in matrix. And the second phase in as-cast alloy are relatively coarse and mostly are distrubuted along grain boundries.

\subsection{Tafel curves}

Fig.4 presents Tafel curves of AZ31 magnesium alloy under different processing conditions immerged in $3.5 \% \mathrm{NaCl}$ solution. Besides the as-cast sample, the other three have similar equilibrium potential. The extruded alloy has the most negative corrosion potential than the rolled and cast-rolled 


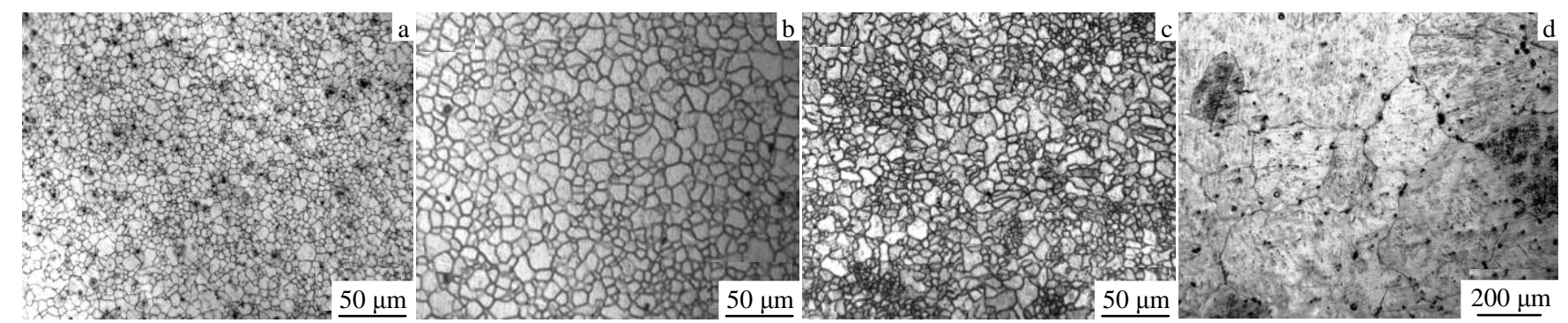

Fig.1 Metallographes of AZ31 magnesium alloy under different processing conditions: (a) extruded, (b) rolled, (c) cast-rolled, and (d) as-cast
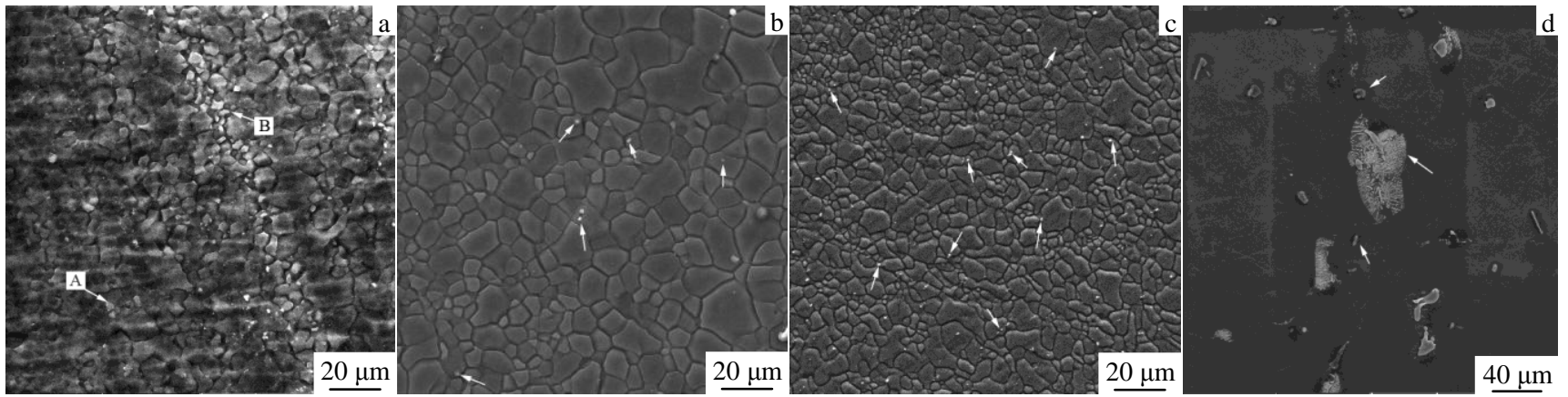

Fig.2 SEM images of AZ31 magnesium alloy under different processing conditions: (a) extruded, (b) rolled, (c) cast-rolled, and (d) as-cast
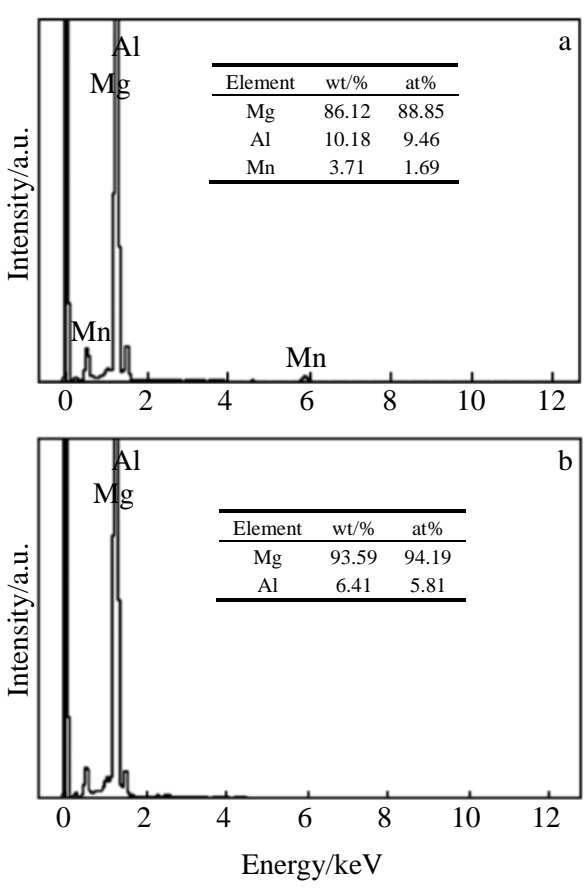

Fig.3 EDS results for point A and B in Fig.2

alloys. That's to say, the extruded magnesium alloy performs high electrochemical activity to a certain extent in a battery. In the cathode polarization curve, the extruded anode has relatively low hydrogen evolution rate, resulting in high anode efficiency. While the activities of the rolled and the cast-rolled are relatively low and the as-cast alloy is the worst. The figures

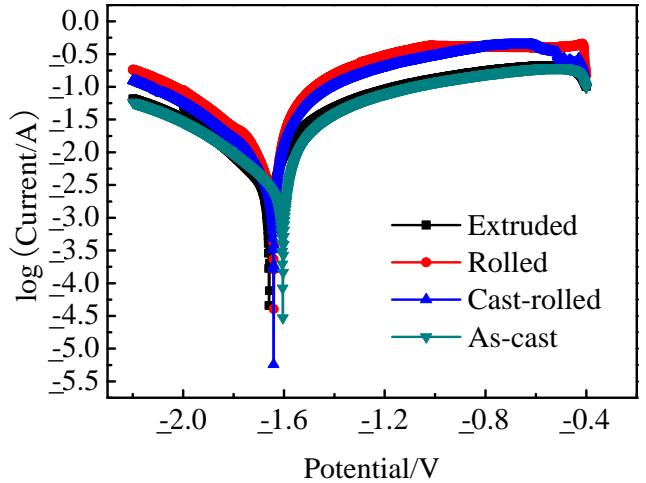

Fig.4 Tafel curves of AZ31 magnesium alloy immersed in $3.5 \% \mathrm{NaCl}$

in Table 1 are related to the polarization. Compared with the rolled and cast-rolled alloys, the extruded AZ31 alloy exhibits a relatively low corrosion current density and high electrochemical activity.

Table 1 Corrosion parameters calculated from polarization test

\begin{tabular}{cccc} 
Materials & $\begin{array}{c}\text { Equilibrium potential, } \\
E_{\text {corr }} / \mathrm{V}\end{array}$ & $\begin{array}{c}\text { Corrosion current, } \\
J_{\text {corr }} / \mathrm{A} \cdot \mathrm{cm}^{-2}\end{array}$ & $\begin{array}{c}\text { Tafel } \\
\text { slope, } \beta\end{array}$ \\
\hline Extruded & -1.66 & $5.59 \times 10^{-3}$ & 5.70 \\
Rolled & -1.64 & $7.33 \times 10^{-3}$ & 6.08 \\
Cast- rolled & -1.64 & $7.01 \times 10^{-3}$ & 5.78 \\
As-cast & -1.60 & $5.26 \times 10^{-3}$ & 5.60 \\
\hline
\end{tabular}




\subsection{Free corrosion test}

The corrosion rates of AZ31 magnesium alloy under different processing conditions immersed in $3.5 \% \mathrm{NaCl}$ solution for $70 \mathrm{~h}$ are shown in Table 2. The extruded sample exhibits the lowest corrosion rate among the four, followed by the rolled and cast-rolled magnesium alloys. The corrosion of the as-cast AZ31 magnesium alloy is heavy. This result is consistent with the polarization curves.

Fig.5 shows the corrosion morphologies of AZ31 magnesium alloy under different processing conditions immersed in $3.5 \% \mathrm{NaCl}$ solution for $70 \mathrm{~h}$. According to the SEM morphology, the surface product of the extruded electrode is granular and disperses loosely. During the discharge process of the extruded material, some products of the electrode can be observed falling into the solution constantly, resulting in the decrease of polarization and a good electrochemical activity of the extruded alloy anode. In addition, there are a few corrosion pits. The cast-rolled and rolled magnesium alloys have more dense corrosion products, and the as-cast electrode has an uneven surface with some corrosion pits after free corrosion. The corrosion of the as-cast magnesium electrode is the most evident. Besides the coarse grains, it is perhaps due to coarse second phase distributed along the grain boundaries and as-cast defects in the as-cast electrode. The second phase always has very positive potential and is easy to become micro-electrode cathode accelerating the corrosion of as-cast substrate. After the self-corrosion process, there are many corrosion pits on the electrode surfaces of the four states, indicating that the corrosion patterns of AZ31 magnesium alloy under different processing conditions are basically pitting corrosion.

\subsection{EIS Measurements}

Fig.6 shows EIS results of AZ31 magnesium alloy under different processing conditions. All the Nyquist plots consist of a high-frequency impedance loop and a low-frequency inductive loop. The high-frequency region reflects the ability of the electron through the two-electrode capacitance (the double layer capacitance between the electrode and solution), which is known as the charge transfer resistance of the electrode reaction. The low-frequency region is due to the adsorption on the electrode surface of the material during the relaxation process. From the Nyquist plots, the shapes of the four material impedance diagrams are similar, with a high-frequency capacitance loop in a-quadrant and a low-frequency inductive loop in four-quadrant. It is indicated that the corrosion mechanism and the factors that influence the corrosion process are the same. From the EIS spectra, the high-frequency capacitance arc radius of the as-cast is the smallest. As we know, high-frequency capacitance arc radius and electric double layer capacitance are in direct proportion, while the electric double layer capacitance is in inverse proportional to material corrosion resistance. Therefore, the as-cast alloy has the worst corrosion resistance. The rolled and cast-rolled magnesium alloys are basically the same. The corrosion resistance of the extruded magnesium alloy is relatively higher than those of the other magnesium alloys, which is consistent with the former results of Tafel curves.

\subsection{Chronopotentiometry}

Fig.7 presents the discharge curves of the magnesium alloy under different processing conditions, determined by chronopotentiometry. It can be seen that the discharge stability of the as-cast alloy is the worst of the four states. The discharge curve of the as-cast material fluctuates constantly and the discharge potential changes rapidly over time. It is believed that the discharge performance has a great relationship with the kind of materials, the number of twins, grain sizes and grain uniformity ${ }^{[15]}$. The as-cast material not only has coarse grains, uneven distribution, but also contains defects and coarse second phase along the grain bounderies.

Table 2 Free corrosion of AZ31 magnesium alloy in $3.5 \% \mathrm{NaCl}$ solution

\begin{tabular}{cc}
\hline Material & Free corrosion rate $/ \mathrm{mA} \cdot \mathrm{cm}^{-2}$ \\
\hline Extruded & 0.054 \\
Rolled & 0.095 \\
Cast-rolled & 0.099 \\
As-Cast & 0.143 \\
\hline
\end{tabular}
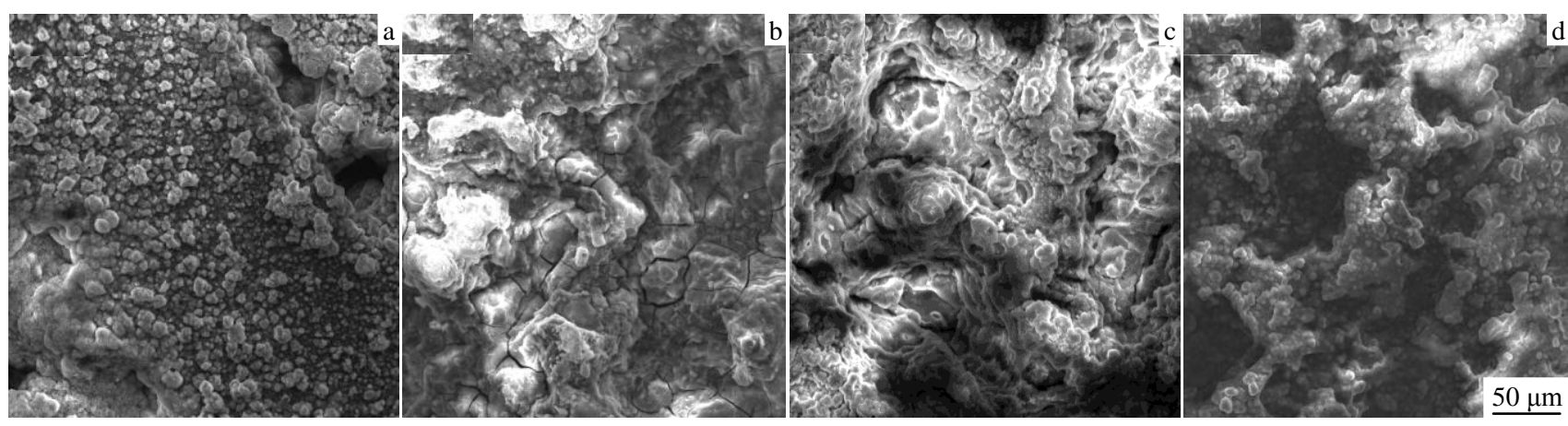

Fig.5 SEM corrosion morphologies of AZ31 magnesium alloy under different processing conditions: (a) extruded, (b) rolled, (c) cast-rolled, and (d) as-cast 


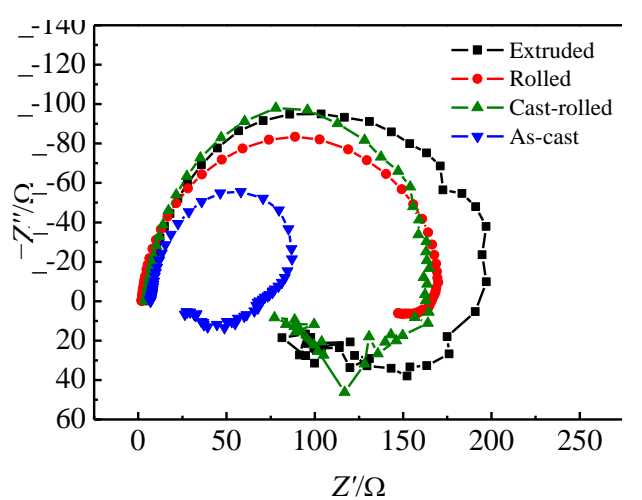

Fig.6 Nyquist plots of AZ31 magnesium alloy immersed in $3.5 \% \mathrm{NaCl}$

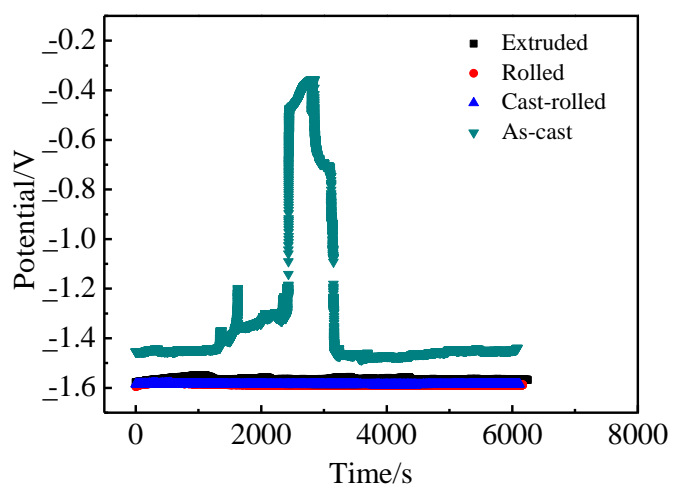

Fig.7 Discharge curves of AZ31 magnesium alloy immersed in $3.5 \% \mathrm{NaCl}$

Impurities have a relatively high potential, are prone to form more galvanic pairs, and therefore speed up the matrix corrosion and reduce the discharge efficiency. Meanwhile, other three states of AZ31 alloy have similar smooth discharge curves with relatively negative potential and good electrochemical activity.

\section{Conclusions}

1) The extruded AZ31 magnesium alloy performs a more negative equilibrium potential and better electrochemical activity than other magnesium alloys in the Tafel curves. It has the lowest corrosion current density and its currosion products are loose and easy to fall off, resulting in small polarization and relatively high utilization of anode.

2) The extruded, the rolled and the cast-rolled of AZ31 magnesium alloy have similar smooth discharge curves with relatively negative potential and good electrochemical activity.

3) The casted AZ31 magnesium alloy as anode material performs the worst performances. The corrosion patterns of AZ31 magnesium alloy corrosion are basically pitting corrosion.

4) Compared with the as-cast, the rolled and the cast-rolled, the extruded AZ31 magnesium alloy with relatively high activity and strong corrosion resistance, is the best costperformance ratio material as the anode material among the four.

\section{References}

1 Cheng Y L, Qin T W, Wang H M. The Chinese Journal of Nonferrous Metals Society[J], 2009, 19: 517 (in Chinese)

2 Kim J G, Joo J H, Koo S E. Journal of Materials Science Letters [J], 2000, 19(6): 477

3 Yee R, Mallory J, Parrish J D et al. Journal of Electroanalytical Chemistry[J], 2006, 593(1-2): 69

4 Bonafoux D, Bordeau M, Biran C et al. Organometallic Chemistry[J], 1995, 493(1-2): 27

5 Parthiban G T, Parthiban T, Ravi R et al. Corrosion Science[J], 2008, 50(12): 3329

6 Koeigsberger R, Parsons S M. Biochemical and Biophysical Research Communications [J], 1980, 94(1): 305

7 Justus S M, Silva S N, Jr F V et al. Ceramics International[J], 2005, 31(7): 897

8 Gerimov K B, Konstanchuck L G, Chizhik S A et al. International Journal of Hydrogen Energy[J], 2009, 34(4): 1916

9 Soloveichik G L, Rijssenbeek J, Andrus M et al. International Journal of Hydrogen Energy[J], 2009, 34(2): 916

10 Tan, Danaie M, Kalisvaart W P et al. International Journal of Hydrogen Energy[J], 2011, 36(3): 2154

11 Mwdeiros M G, Dow E G. Journal of Power Sources[J], 1999, 80: 78

12 Tacikoeski M, Kaminski J, Rudnicki J et al. Vacuum[J], 2011, 85(10): 938

13 Pardo A, Merino M C, Coy A E et al. Corrosion Science[J], 2008, 50(3): 23

14 Sivashanmugam A, Prem Kumar T, Renganathan N G. Journal of Applied Electrochemistry[J], 2004, 34(11): 1135

15 Popovich N A, Govind R. Journal of Power Sources[J], 2002, 112(1): 36

16 Anik M, Celikten G. Corrosion Science[J], 2007, 49(4): 1878

17 Naing N A, Wei Z. Corrosion Science[J], 2010, 52(2): 589 


\title{
不同加工状态 AZ31 镁合金电化学性能研究
}

\author{
邓金风 ${ }^{1}$, 黄光胜 ${ }^{1,2}$, 赵炎春 ${ }^{1}$ ，王 蓓 ${ }^{1}$
}

(1. 重庆大学 国家镁合金材料工程技术研究中心，重庆 400045)

(2. 重庆科学技术研究院 重庆新材料研究中心, 重庆 401123)

\begin{abstract}
摘 要: 为选择一种高性价比的镁电池阳极材料, 借助电化学工作站、光学显微镜 (OM)、扫描电子显微镜 (SEM) 和 X 射线能谱分析 (EDS) 对不同加工状态的 AZ31B 镁合金电化学性能进行研究。分别将挤压、轧制、铸轧和铸态 AZ31B 镁合金作为阳极材料, 测试其 电化学性能。结果表明, 在 4 种加工状态下, 挤压态镁合金是性价比最高的一种阳极材料; 其组织由均匀细小的晶粒和第二相组成, 拥有最负的平衡电位, 最低腐蚀电流密度和最小自腐蚀速率; 挤压态样品腐蚀后, 表面产生疏松细小, 且均匀分布的腐蚀产物, 降低了 阳极极化, 增加了阳极利用率。轧制和铸轧态的 AZ31B 镁合金的电化学活性和耐蚀性能相对挤压态的较低。铸态 AZ31B 镁合金由于较 粗大的晶粒、第二相和铸造缺陷, 表现出不稳定的放电曲线和较正的放电电位。不同状态 AZ31 镁合金的腐蚀均以点蚀为主。
\end{abstract}

关键词: AZ31 镁合金; 电流密度; 放电; 腐蚀

作者简介: 邓金凤, 女, 1987 年生, 硕士, 重庆大学材料科学与工程学院, 重庆 400045, 电话: 023-65112239, E-mail: 448744467@qq.com 